\title{
Significances of Peripheral Inflammatory Cells and Neutrophil/Platelet-Lymphocyte Ratio in Breast Cancer after Resection
}

\author{
Pi-Fang Chen1, Chun-Chaing Lee1, Ching-Kuen Pan², Chen-Guo Ker², Yu-Fu Chen ${ }^{3}$, \\ Bo-Wei Wang", Chin-Yi Chao", Chia-Ling Lu${ }^{4}$ \\ ${ }^{1}$ Department of Family Medicine, Yuan's General Hospital, Taiwan \\ ${ }^{2}$ Department of Surgery, Yuan's General Hospital, Taiwan \\ ${ }^{3}$ Department of Medical Education and Research, Yuan's General Hospital, Taiwan \\ ${ }^{4}$ Department of Cancer Resource Center, Yuan's General Hospital, Taiwan \\ Email: *kercg@yuanhosp.com.tw
}

How to cite this paper: Chen, P.-F., Lee, C.-C., Pan, C.-K., Ker, C.-G., Chen, Y.-F., Wang, B.-W., Chao, C.-Y. and Lu, C.-L. (2020) Significances of Peripheral Inflammatory Cells and Neutrophil/Platelet-Lymphocyte Ratio in Breast Cancer after Re- section. Journal of Biosciences and Medicines, $\mathbf{8}$, 47-62.

https://doi.org/10.4236/jbm.2020.810006

Received: August 20, 2020

Accepted: October 16, 2020

Published: October 19, 2020

Copyright $\odot 2020$ by author(s) and Scientific Research Publishing Inc. This work is licensed under the Creative Commons Attribution International License (CC BY 4.0).

http://creativecommons.org/licenses/by/4.0/ (c) (i) Open Access

\begin{abstract}
Introduction: Breast cancer had become top leading cause of death in Taiwan and endangered women's health worldwide. Therefore, we try to invest the peripheral inflammatory cell counts and neutrophil-lymphocyte ratio (NLR) and platelet-lymphocyte ratio (PLR) from our routine practice for the predictor of prognosis of breast cancer after resection. Patients and Methods: There were 574 breast cancer patients accepted surgical resection and registered in Cancer Registry Center of our hospital. Patient's basic profiles, peripheral neutophil, lymphocyte and platelet count were measured for study. The scales of NLR and PLR were derived from the lower and higher normal range in cell count from neutrophil, lymphocyte and platelet respectively. Therefore, the scales for NLR and PLR were $\leq 1.62,1.63-2.57, \geq 2.58$ and $\leq 224,225-253, \geq 254$ respectively for analysis. Results: Poor 5-yr survival rate was found if higher cell counts of neutrophil and platelet ( $\leq 0.05)$. Three scales of NLR were $\leq 1.62,1.63-2.57, \geq 2.58$, and their 5-year survival rates were $94 \%, 91 \%$ and $84 \%$ respectively $(\mathrm{p}=0.019)$. In the subgroup of HER-2 (negative), and 3-Negative breast patients had a higher NLR of poor prognosis. But higher PLR was found less in 3-Negative and non in 3-Positive patients $(\mathrm{p}=0.039)$. The PLR was $\leq 224,225-253, \geq 254$ and their 5 -year survival rates were $92 \%, 87 \%$, and $64 \%$ respectively $(\mathrm{p}=0.001)$; Multivariate Cox regression model for predictor of breast cancer patients who have 3.39 (PLR $\geq 254)$ and 2.45 (NLR $\geq 2.58)$ times risk $(\mathrm{p}=0.02$ and $\mathrm{p}=0.002)$ of poor prognosis respectively. Conclusion: Peripheral inflammatory cell counts are easily to take in our clinical practice and have a potential role as predictors of
\end{abstract}


prognosis. We have to pay attention to the trends of peripheral inflammatory cell count and their ratio in our clinical practice where possible.

\section{Keywords}

Inflammatory Cell, Neutrophil-Lymphocyte Ratio, Platelet-Lymphocyte

Ratio, Cancer Prognosis, Survival Rate

\section{Introduction}

Breast cancer had endangered women's health worldwide and had been as the first causes of death of women in Taiwan for several years [1]. Pretreatment imaging, laboratory tests and surgical procedures remain the main methods used for evaluation of the prognosis [2] [3]. Theoretically, the inflammatory cells role as one of the important parts of tumor progression which had been mentioned for decades [4] [5]. Tumor micro-environment regulated by inflammatory cells clearly plays a basic influence on the neoplastic process, stimulation of proliferation, migration and survival [5] [6]. The inflammatory component of a developing neoplasm may include a diverse leukocyte population such as neutrophils, macrophages, and lymphocytes [6] [7].

Platelets can release a variety of contents that can both inhibit and stimulate angiogenesis, immune-surveillance, or neoplasm growth through the releasing some growth factors such as platelet derived growth factor, platelet factor IV and thrombospondin [8] [9]. In addition, platelets can play important roles in immune escape in hematogenous tumor spread and lead to tumor cell adhesion, invasion and tumor progression [10]. In the previous reports, predictor of better or poor survive with neutrophil/lymphocyte ratio (NLR) or platelate/lymphocyte ration (PLR) was demonstrated in breast cancer or even other solid tumors [11] [12] [13] [14] [15]. The measurement of the systemic inflammatory response had been refined using modified Glasgow Prognostic Score including the NLR or PLR to have prognostic value and independently association with survival in all cancers [16]. In univariate analysis by Ramos [17], an NLR $>3$ was associated with poor overall survive $(\mathrm{p}<0.001)$ and PLR $>250$ was associated with worse overall survive ( $\mathrm{p}<0.001)$. However, after adjustment for potential confounders, only the PLR was more independently associated with worse outcomes. In the study of Fujii [18], they demonstrated that the finding of either a high FDG uptake in PET-CT scanning in breast tumor or a high NLR may be predictive of aggressive features and a reflection of poor prognosis among breast cancer patients. Prognostic significance for NLR PLR, and lymphocyte was simple predictors that might be useful for identifying patients who have high recurrence risk, and those that are candidates for additional treatments [19]. Therefore, we conduct this study to invest the inflammatory cells counts including the neutrophil, lymphocyte, platelet, NLR and PLR in the prognosis of breast cancer patients. 


\section{Patients and Methods}

Breast cancer patients who were accepted surgical resection were 574 registered in Cancer Registry Center of our hospital from 2006 to 2011 and follow-up at least for 5 years in this study. All patients were confirmed diagnosis based on the cancer treatment guideline, and registered under the surveillance care program in our Cancer Registration Center. The clinical features include patient's basic profiles, and neutophil, lymphocyte and platelet cell count in the peripheral blood at the time of diagnosis were measured. The optimal cut-off from normal range of neutrophil, lymphocyte, and platelet were $43 \%-71 \%(1720-2840 / \mathrm{dl})$, $16.7 \%-43.4 \%$ (668 - 1736/dl), and 150,000 - 440,000/dl in cell count respectively in our hospital, Therefore, the scales of NLR and PLR were derived from the lower normal range and higher normal range of cell count for neutrophil, lymphocyte and platelet respectively. Three scales of NLR were $\leq 1.62,1.63-2.57$, $\geq 2.58$, and of PLR were $\leq 224,225-253, \geq 254$ respectively of breast cancer. The 1 -yr, 3-yr, and 5-year survival rates and their recurrent rates were analyzed according to the scales and variable factors including age, TMN stage, grading, vessel infiltration, lymph-node metastasis, positive rate of ER, PR, and HER2, and subtype (3-positive and 3-negative).

These results are presented as mean \pm SE and Kaplan-Meier analysis for their survival rates. Statistical analysis was performed with an unpaired Student's t test after ANOVA for more than two groups in each cancer group. The $P$ values less than 0.05 were considered to be significant.

\section{Results}

1) Netrophil, Lymphocyte, and Platelet Counts in Breast Cancer Patients.

Mean survive time effected by peripheral neutrophil, lymphocyte, and platelet cell were listed in Table 1 . Survival rate divided by scale of neutrophil, lymphocyte, and platelet were shown in Figures 1(a)-(c). Poor 5-yr survival rates were found if higher cell counts of neutrophil and platelet with a significant difference ( $\mathrm{p} \leq 0.05)$. On the contrary, the 5 -year survival rate was poor if lymphocyte cell counts was less than $16.6 \%$ as Table 1 and Figure $1(b)$.

2) N/L Ratio in Breast Cancer Patients.

NLR and the variable factors of breast cancer were shown in Table 2. The higher NLR were found in the group of HER-2 (negative), and 3-Negative breast cancer patients. There was none high NLR in 3-Positive breast cancer $(\mathrm{p}<0.01)$. The NLR of breast cancers and their survival times and rates were listed in Table 2 , The NLR was $\geq 2.58$, the 5 -year survival rates was poor prognosis than that of other two groups $(\mathrm{p}=0.019)$. There were $11(5.9 \%), 16(9.2 \%)$, and $19(15.4 \%)$ death within 5 years after operation found in the patients with PLR $\leq 224,225$ 253 , and $\geq 254$ respectively. Their mean survival times were shorter in the patients of high score of NLR $\geq 2.58$. The 1-yr, 3-yr, and 5-yr survival rates and curves demonstrated poor prognosis with higher NLR in Table 3 and Figure 2. Multivariate Cox regression model for predictor of prognosis were found poor 
Table 1. Survival rates according to the scale of neutrophil, lymphocyte, and platelet.

\begin{tabular}{|c|c|c|c|c|c|c|c|}
\hline \multirow{2}{*}{ Neutrophil (\%) } & \multirow{2}{*}{$\mathrm{N}$} & \multirow{2}{*}{ Death } & \multicolumn{2}{|c|}{ Survival months } & \multicolumn{3}{|c|}{ Survival rate (\%) } \\
\hline & & & Mean & SE & $1 \mathrm{yr}$ & $3 \mathrm{yr}$ & $5 \mathrm{yr}$ \\
\hline$\leq 42$ & 136 & 3 & 77.9 & 0.66 & 99 & 98 & 98 \\
\hline $43-71$ & 386 & 31 & 123.5 & 1.47 & 97 & 93 & 90 \\
\hline$\geq 72$ & 46 & 13 & 83.1 & 5.92 & 85 & 73 & 69 \\
\hline \multirow{2}{*}{ Lymphocyte (\%) } & \multirow{2}{*}{$\mathrm{N}$} & \multirow{2}{*}{ Death } & \multicolumn{2}{|c|}{ Survival months } & \multicolumn{3}{|c|}{ Survival rate (\%) } \\
\hline & & & Mean & SE & $1 \mathrm{yr}$ & $3 \mathrm{yr}$ & $5 \mathrm{yr}$ \\
\hline$\leq 16.6$ & 31 & 10 & 54.5 & 4.54 & 81 & 71 & 64 \\
\hline $16.7-43.4$ & 516 & 35 & 124.8 & 1.18 & 97 & 94 & 92 \\
\hline$\geq 43.5$ & 27 & 2 & 76 & 2.16 & 100 & 96 & 89 \\
\hline \multirow{2}{*}{ Platelet $\left(10^{3}\right)$} & \multirow{2}{*}{$\mathrm{N}$} & \multirow{2}{*}{ Death } & \multicolumn{2}{|c|}{ Survival months } & \multicolumn{3}{|c|}{ Survival rate (\%) } \\
\hline & & & Mean & SE & $1 \mathrm{yr}$ & $3 \mathrm{yr}$ & $5 \mathrm{yr}$ \\
\hline$\leq 149$ & 21 & 4 & 77.9 & 4.95 & 95 & 85 & 76 \\
\hline $150-440$ & 561 & 43 & 123.7 & 1.22 & 96 & 93 & 91 \\
\hline$\geq 441$ & 11 & 3 & 62.8 & 6.6 & 91 & 81 & 63 \\
\hline
\end{tabular}

Table 2. Descriptive information of breast cancer patients divided into three scales according to the $\mathrm{N} / \mathrm{L}$ ratio and variates.

\begin{tabular}{|c|c|c|c|c|c|c|c|c|}
\hline \multirow{2}{*}{ Variate } & \multirow{2}{*}{ Stratification } & \multirow{2}{*}{\multicolumn{2}{|c|}{$\begin{array}{c}\mathrm{N} / \mathrm{L} \leq 1.62 \\
\mathrm{~N}=187\end{array}$}} & \multirow{2}{*}{\multicolumn{2}{|c|}{$\begin{array}{c}\mathrm{N} / \mathrm{L} 1.63-2.57 \\
\mathrm{~N}=174\end{array}$}} & \multirow{2}{*}{\multicolumn{2}{|c|}{$\begin{array}{c}\mathrm{N} / \mathrm{L} \geq 2.58 \\
\mathrm{~N}=123\end{array}$}} & \multirow{2}{*}{$\mathrm{P}$ value } \\
\hline & & & & & & & & \\
\hline Age & $(\mathrm{M} \pm \mathrm{SD})$ & \multicolumn{2}{|c|}{$54.3 \pm 10.6$} & \multicolumn{2}{|c|}{$52.4 \pm 11.6$} & \multicolumn{2}{|c|}{$51.7 \pm 10.7$} & 0.094 \\
\hline \multirow[t]{4}{*}{ Stage } & I & 78 & 41.7 & 59 & 33.9 & 43 & 35 & 0.173 \\
\hline & II & 72 & 38.5 & 78 & 44.8 & 46 & 37.4 & \\
\hline & III & 28 & 15 & 31 & 17.8 & 22 & 17.9 & \\
\hline & IV & 9 & 4.8 & 6 & 3.4 & 12 & 9.8 & \\
\hline \multirow[t]{4}{*}{ Grade } & well & 37 & 19.8 & 38 & 21.8 & 32 & 26.0 & 0.205 \\
\hline & moderately & 105 & 56.1 & 85 & 48.9 & 51 & 41.5 & \\
\hline & poorly & 32 & 17.1 & 34 & 19.5 & 23 & 18.7 & \\
\hline & unknown & 13 & 7 & 17 & 9.8 & 17 & 13.8 & \\
\hline \multirow{3}{*}{ Vessel (+) } & No & 123 & 65.8 & 118 & 67.8 & 79 & 64.2 & 0.048 \\
\hline & Yes & 56 & 29.9 & 51 & 29.3 & 37 & 30.1 & \\
\hline & unknown & 8 & 4.2 & 5 & 2.8 & 7 & 5.7 & \\
\hline LN (+) count. & $(\mathrm{M} \pm \mathrm{SD})$ & \multicolumn{2}{|c|}{$12.5 \pm 8.0$} & \multicolumn{2}{|c|}{$13.7 \pm 7.3$} & \multicolumn{2}{|c|}{$11.8 \pm 7.0$} & 0.082 \\
\hline \multirow[t]{3}{*}{$\mathrm{LN}(+)$} & No & 110 & 58.8 & 98 & 56.3 & 70 & 56.9 & 0.759 \\
\hline & Yes & 72 & 38.5 & 73 & 42 & 48 & 39 & \\
\hline & unknown & 5 & 2.7 & 3 & 1.7 & 5 & 4.1 & \\
\hline \multirow[t]{2}{*}{ ER } & Positive & 133 & 72.7 & 114 & 65.9 & 91 & 75.8 & 0.149 \\
\hline & Negative & 50 & 27.3 & 59 & 34.1 & 29 & 24.2 & \\
\hline \multirow[t]{2}{*}{ PR } & Positive & 118 & 64.8 & 104 & 60.1 & 80 & 66.1 & 0.509 \\
\hline & Negative & 64 & 35.2 & 69 & 39.9 & 41 & 33.9 & \\
\hline \multirow[t]{2}{*}{ Her-2 } & Positive & 52 & 28.4 & 54 & 31.4 & 19 & 15.7 & $0.008^{*}$ \\
\hline & Negative & 131 & 71.6 & 118 & 68.6 & 102 & 84.3 & \\
\hline Subtype & 3-Positive & 11 & 9.9 & 0 & 0 & 0 & 0 & $<0.001^{\star}$ \\
\hline
\end{tabular}




\begin{tabular}{|c|c|c|c|c|c|c|c|c|}
\hline \multicolumn{9}{|l|}{ Continued } \\
\hline & 3-Negative & 21 & 18.9 & 30 & 56.6 & 21 & 77.8 & \\
\hline & Others & 79 & 71.2 & 23 & 43.4 & 6 & 22.2 & \\
\hline $\mathrm{WBC} \times 10^{3}$ & $(\mathrm{M} \pm \mathrm{SD})$ & \multicolumn{2}{|c|}{$6.6 \pm 2.0$} & \multicolumn{2}{|c|}{$7.1 \pm 1.5$} & \multicolumn{2}{|c|}{$7.7 \pm 2.3$} & $<0.001^{*}$ \\
\hline Platalate $\times 10^{3}$ & $(\mathrm{M} \pm \mathrm{SD})$ & \multicolumn{2}{|c|}{$241.6 \pm 75.3$} & \multicolumn{2}{|c|}{$267.2 \pm 61.5$} & \multicolumn{2}{|c|}{$269.4 \pm 86.5$} & $0.001^{*}$ \\
\hline Neutrophil & $(\mathrm{M} \pm \mathrm{SD})$ & \multicolumn{2}{|c|}{$3780 \pm 1701.3$} & \multicolumn{2}{|c|}{$4311 \pm 983.8$} & \multicolumn{2}{|c|}{$5458.0 \pm 1901.1$} & $<0.001^{\star}$ \\
\hline Lymphocyte & $(\mathrm{M} \pm \mathrm{SD})$ & \multicolumn{2}{|c|}{$2218.1 \pm 700.7$} & \multicolumn{2}{|c|}{$2122.8 \pm 489.0$} & \multicolumn{2}{|c|}{$1529.8 \pm 426.6$} & $<0.001^{\star}$ \\
\hline Recurrent & Yes & 18 & 9.6 & 23 & 13.2 & 14 & 11.4 & 0.561 \\
\hline \multirow{3}{*}{ Status } & No & 169 & 90.4 & 151 & 86.8 & 109 & 88.6 & \\
\hline & Death & 11 & 5.9 & 16 & 9.2 & 19 & 15.4 & $0.019^{*}$ \\
\hline & Alive & 176 & 94.4 & 158 & 90.8 & 104 & 84.6 & \\
\hline
\end{tabular}

${ }^{*} \mathrm{P}<0.05$.

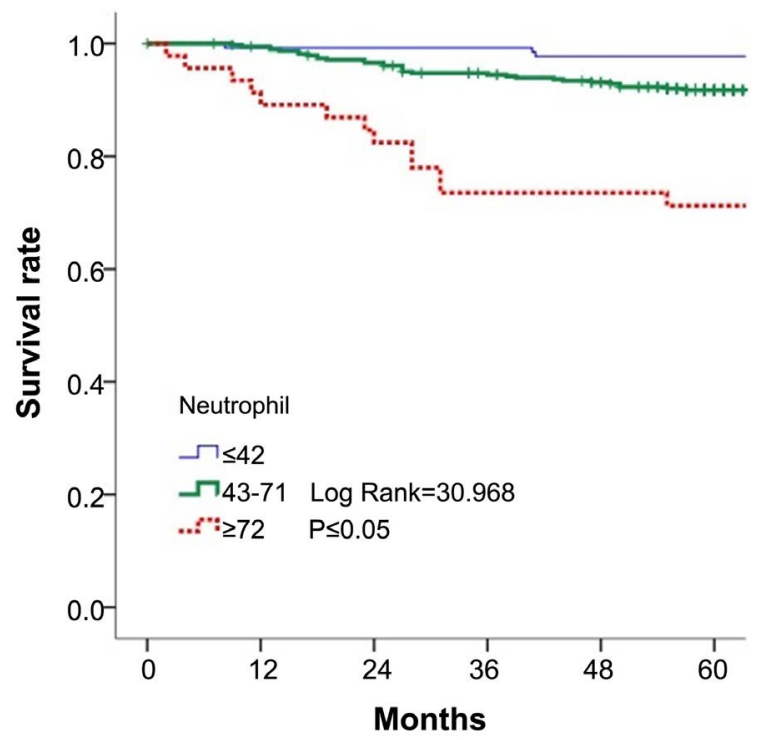

(a)

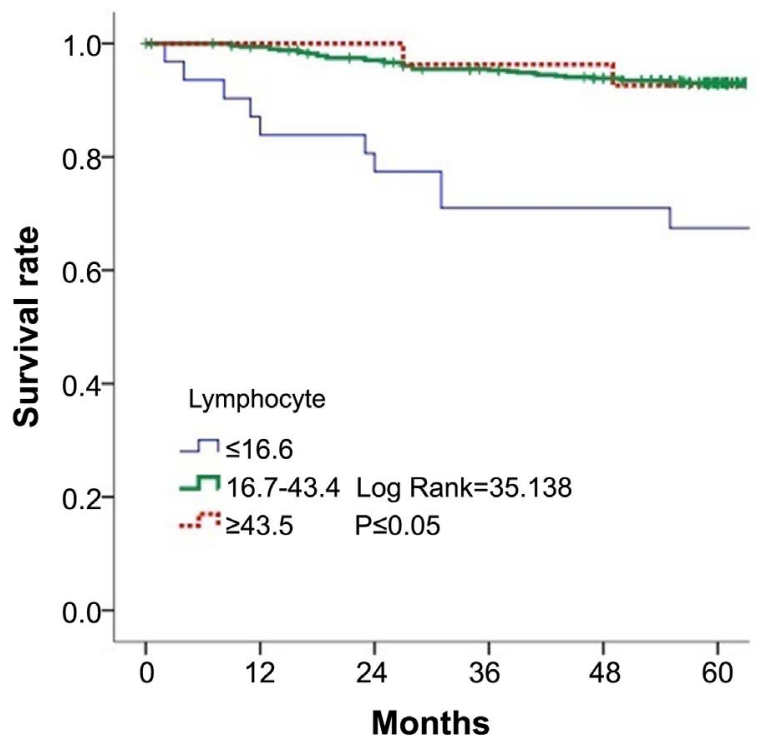

(b) 


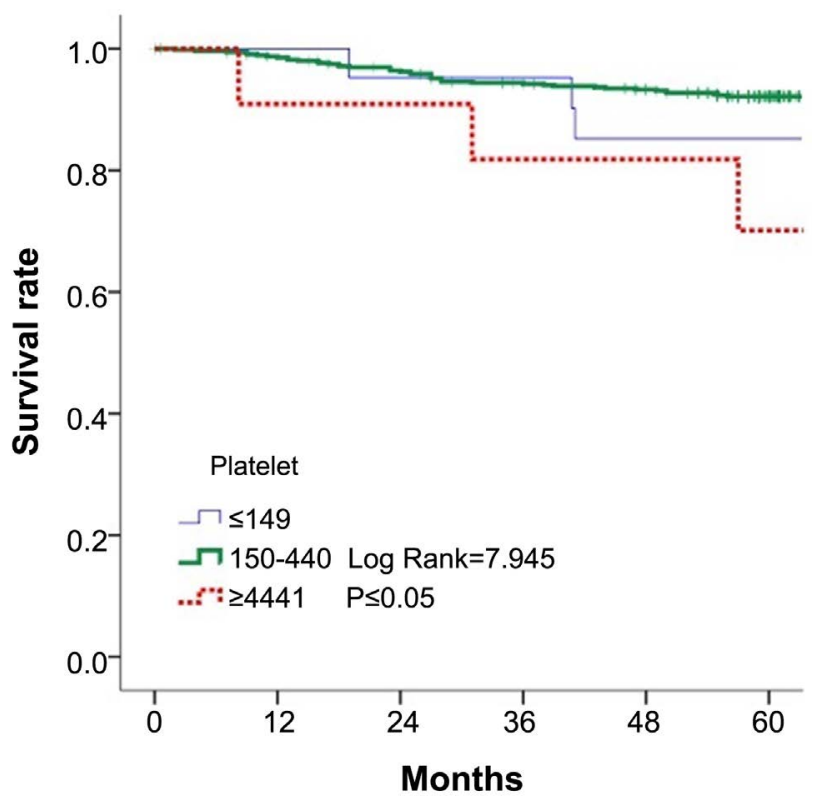

(c)

Figure 1. Analysis of 5-year survival rate with Kaplan-Meier method in breast cancer patients divided into three scales of neutrophil (a), lymphocyte (b), and palatelet (c) and revealed a significant difference of survival rate of (a) $\mathrm{X}^{2}=30.968, \mathrm{P} \leq 0.05$, (b) $\mathrm{X}^{2}=35.138$, $\mathrm{P} \leq 0.05$ and $(\mathrm{c}) \mathrm{X}^{2}=7.945, \mathrm{P} \leq 0.05$ in each group.

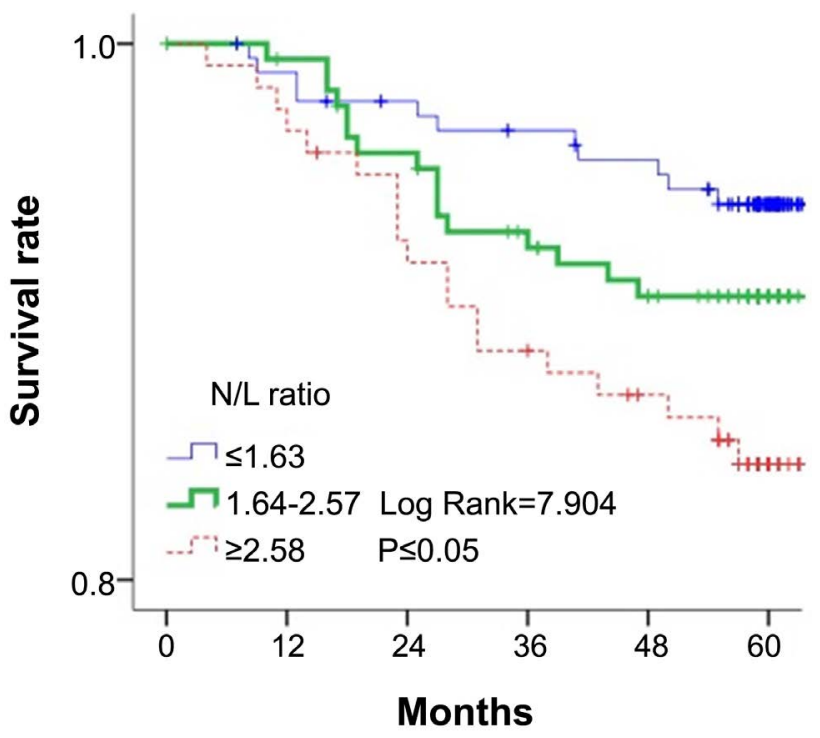

Figure 2. Analysis of five-year survival rate of Kaplan-Meier method in breast cancer patients divided into three scales according $\mathrm{N} / \mathrm{L}$ ratio $(\mathrm{P} \leq 0.019)$ with Log-rant test.

in the TMN stage IV having Hazard ratio of $28.56(\mathrm{p}=0.001)$, and NLR $>2.58$ to having 2.45 times risk of poor prognosis $(\mathrm{p}=0.021)$ than other groups as shown in Table 4. There was no different prognosis concerning operative method.

3) $P / L$ Ratio in Breast Cancer Patients

The descriptive information variable factors and PLR of breast cancer patients were shown in Table 5. The lower PLR were found in the group of low lymph 
Table 3. Analysis of five-year survival rate of Kaplan-Meier method in breast cancer patients divided into three groups according N/L ratio.

\begin{tabular}{cccccccc}
\hline \multirow{2}{*}{$\mathrm{N} / \mathrm{L}$} & $\mathrm{N}$ & Death & \multicolumn{2}{c}{ Survival months } & \multicolumn{3}{c}{ Survival rate (\%) } \\
\cline { 5 - 8 } & & & Mean & $\mathrm{SE}$ & $1 \mathrm{yr}$ & $3 \mathrm{yr}$ & $5 \mathrm{yr}$ \\
\hline$\leq 1.62$ & 187 & 11 & 76.1 & 0.9 & 99 & 97 & 94 \\
1.63 to 2.57 & 174 & 16 & 122 & 2.4 & 99 & 93 & 91 \\
$\geq 2.58$ & 123 & 19 & 95.4 & 2.7 & 98 & 89 & 84 \\
\hline
\end{tabular}

Table 4. Multivariate Cox regression model for predictor of prognosis of breast cancer.

\begin{tabular}{|c|c|c|c|c|c|}
\hline \multirow{2}{*}{ Variate } & \multirow{2}{*}{$\beta$} & \multirow{2}{*}{ Hazard ratio } & \multicolumn{2}{|c|}{$95 \% \mathrm{CI}$ of $\mathrm{HR}$} & \multirow{2}{*}{$\mathrm{P}$ value } \\
\hline & & & Lower & Upper & \\
\hline Age & 0.048 & 1.049 & 1.021 & 1.077 & $<0.001^{\star}$ \\
\hline \multicolumn{6}{|l|}{ Stage } \\
\hline I (ref.) & & 1 & & & \\
\hline II & 1.25 & 3.489 & 1.134 & 10.741 & $0.029^{*}$ \\
\hline III & 1.932 & 6.905 & 2.175 & 21.929 & $0.001^{*}$ \\
\hline IV & 3.352 & 28.565 & 8.849 & 92.209 & $0.001^{\star}$ \\
\hline \multicolumn{6}{|l|}{$\mathrm{N} / \mathrm{L}$ ratio } \\
\hline$\leq 1.62$ (ref.) & & 1 & & & \\
\hline 1.63 to 2.57 & 0.624 & 1.866 & 0.857 & 4.063 & 0.116 \\
\hline$\geq 2.58$ & 0.897 & 2.453 & 1.142 & 5.269 & $0.021^{*}$ \\
\hline \multicolumn{6}{|l|}{ OP type } \\
\hline BCS (ref.) & & 1 & & & \\
\hline MRM & 0.03 & 1.030 & 0.300 & 3.531 & 0.962 \\
\hline
\end{tabular}

${ }^{*} \mathrm{P}<0.05$. BCS: breast conservative surgery. MRM: modified radical mastectomy.

Table 5. Descriptive information of breast cancer patients divided into three scales according $\mathrm{P} / \mathrm{L}$ ratio and variates.

\begin{tabular}{|c|c|c|c|c|c|c|c|c|}
\hline \multirow{2}{*}{ Variate } & \multirow{2}{*}{ Stratification } & \multicolumn{2}{|c|}{$\mathrm{P} / \mathrm{L} \leq 224$} & \multicolumn{2}{|c|}{$\mathrm{P} / \mathrm{L} 225$ - 253} & \multicolumn{2}{|c|}{$\mathrm{P} / \mathrm{L} \geq 254$} & \multirow{2}{*}{$P$ value } \\
\hline & & \multicolumn{2}{|c|}{$\mathrm{N}=440$} & \multicolumn{2}{|c|}{$N=16$} & \multicolumn{2}{|c|}{$\mathrm{N}=28$} & \\
\hline Age & $(\mathrm{M} \pm \mathrm{SD})$ & \multicolumn{2}{|c|}{$53.1 \pm 11.0$} & \multicolumn{2}{|c|}{$52.3 \pm 12.3$} & \multicolumn{2}{|c|}{$52 \pm 11.3$} & 0.796 \\
\hline \multirow[t]{4}{*}{ Stage } & I & 170 & 38.6 & 4 & 25 & 6 & 21.4 & $0.001^{\star}$ \\
\hline & II & 180 & 40.9 & 9 & 56.3 & 7 & 25 & \\
\hline & III & 71 & 16.1 & 3 & 18.8 & 7 & 25 & \\
\hline & IV & 19 & 4.3 & 0 & 0 & 8 & 28.6 & \\
\hline \multirow[t]{4}{*}{ Grade } & well & 100 & 22.7 & 4 & 25 & 3 & 10.7 & 0.94 \\
\hline & moderately & 222 & 50.5 & 8 & 50 & 11 & 39.3 & \\
\hline & poorly & 80 & 18.2 & 2 & 12.5 & 7 & 25 & \\
\hline & unknown & 38 & 8.6 & 2 & 12.5 & 7 & 25 & \\
\hline
\end{tabular}




\section{Continued}

\begin{tabular}{|c|c|c|c|c|c|c|c|c|}
\hline \multirow[t]{3}{*}{ Vessel (+) } & No & 300 & 68.2 & 8 & 50 & 12 & 42.9 & \multirow[t]{3}{*}{$0.02^{\star}$} \\
\hline & Yes & 124 & 28.2 & 8 & 50 & 12 & 42.9 & \\
\hline & unknown & 16 & 3.7 & 0 & 0 & 4 & 14.2 & \\
\hline $\mathrm{LN}(+)$ count & $(\mathrm{M} \pm \mathrm{SD})$ & \multicolumn{2}{|c|}{$13 \pm 7.5$} & \multicolumn{2}{|c|}{$12.0 \pm 4.5$} & \multicolumn{2}{|c|}{$10.5 \pm 6.9$} & 0.203 \\
\hline \multirow{3}{*}{$\mathrm{LN}(+)$} & No & 256 & 58.2 & 9 & 56.3 & 13 & 46.4 & 0.464 \\
\hline & Yes & 173 & 39.3 & 7 & 43.8 & 13 & 46.4 & \\
\hline & unknown & 11 & 2.5 & 0 & 0 & 2 & 7.1 & \\
\hline \multirow[t]{2}{*}{ ER } & Positive & 314 & 72.2 & 9 & 56.3 & 15 & 60 & 0.178 \\
\hline & Negative & 121 & 27.8 & 7 & 43.8 & 10 & 40 & \\
\hline \multirow[t]{2}{*}{$P R$} & Positive & 276 & 63.6 & 9 & 56.3 & 17 & 65.4 & 0.817 \\
\hline & Negative & 158 & 36.4 & 7 & 43.8 & 9 & 34.6 & \\
\hline \multirow[t]{2}{*}{ Her-2 } & Positive & 117 & 26.9 & 4 & 25 & 4 & 16 & 0.481 \\
\hline & Negative & 318 & 73.1 & 12 & 75 & 21 & 84 & \\
\hline \multirow[t]{3}{*}{ Subtype } & 3-Positive & 10 & 5.7 & 1 & 14.3 & 0 & 0 & $0.039^{\star}$ \\
\hline & 3-Negative & 62 & 35.6 & 6 & 85.7 & 4 & 40 & \\
\hline & Others & 102 & 58.6 & 0 & 0 & 6 & 60 & \\
\hline $\mathrm{WBC} \times 10^{3}$ & $(\mathrm{M} \pm \mathrm{SD})$ & \multicolumn{2}{|c|}{$7.0 \pm 1.8$} & \multicolumn{2}{|c|}{$7.1 \pm 1.7$} & \multicolumn{2}{|c|}{$7.3 \pm 3.7$} & 0.847 \\
\hline Platalate $\times 10^{3}$ & $(\mathrm{M} \pm \mathrm{SD})$ & \multicolumn{2}{|c|}{$248.37 \pm 59.7$} & \multicolumn{2}{|c|}{$322.4 \pm 94$} & \multicolumn{2}{|c|}{$340 \pm 142.8$} & $0.001^{*}$ \\
\hline Neutrophil & $(\mathrm{M} \pm \mathrm{SD})$ & \multicolumn{2}{|c|}{$4299.9 \pm 1484$} & \multicolumn{2}{|c|}{$5120.4 \pm 1492.1$} & \multicolumn{2}{|c|}{$5519 \pm 3385.4$} & $0.001^{\star}$ \\
\hline Lymphocyte & $(\mathrm{M} \pm \mathrm{SD})$ & \multicolumn{2}{|c|}{$2088 \pm 598.4$} & \multicolumn{2}{|c|}{$1358.0 \pm 373.4$} & \multicolumn{2}{|c|}{$1139.7 \pm 364.8$} & $0.001^{\star}$ \\
\hline \multirow[t]{2}{*}{ Recurrent } & Yes & 49 & 11.1 & 3 & 18.8 & 3 & 10.7 & 0.637 \\
\hline & No & 391 & 88.9 & 13 & 81.3 & 25 & 89.3 & \\
\hline \multirow[t]{2}{*}{ Status } & Death & 34 & 7.7 & 2 & 12.5 & 10 & 35.7 & $0.001^{*}$ \\
\hline & Alive & 406 & 92.3 & 14 & 87.5 & 18 & 64.3 & \\
\hline
\end{tabular}

${ }^{\star} \mathrm{P}<0.05, \mathrm{BCS}$ : breast conservative surgery. MRM: modified radical mastectomy.

vessel involvement and low positive lymph-node metastasis, Higher PLR was found less in 3-Negative breast cancer and none in 3-Positive breast cancer ( $\mathrm{p}=$ 0.039 ). The PLR of breast cancers and their survival times and rates were listed in Table 6 and Figure 3, The PLR was $\geq 254$, the 5-year survival rates were poor in prognosis than that of other two groups $(\mathrm{p}=0.001)$ (Figure 2$)$. There were 34 (7.7\%), 2 (12.5\%), and 10 (35.7\%) were death within 5 years after operation in the patients with PLR $\leq 224,225-253$, and $\geq 254$ respectively $(\mathrm{p}<0.001)$. Their mean survival times were shorter in the patients of high score of NLR $\geq 2.58$. The 1-, 3-, and 5-yr survival curves demonstrated poor prognosis with higher NLR in Table 5 and Figure 2. Multivariate Cox regression model for predictor of prognosis were found poor in the TMN stage IV having 22.1 times risk than other grades $(\mathrm{p}=0.001)$, and PLR $>254$ to having 3.39 times poor prognosis respectively than other groups $(\mathrm{p}=0.002)$ as shown in Table 7 . 
Table 6. Analysis of five-year survival rate of Kaplan-Meier method in breast cancer patients divided into three groups according $\mathrm{P} / \mathrm{L}$ ratio.

\begin{tabular}{cccccccc}
\hline \multirow{2}{*}{$\mathrm{P} / \mathrm{L}$} & \multirow{2}{*}{$\mathrm{N}$} & Death & \multicolumn{2}{c}{ Survival months } & \multicolumn{3}{c}{ Survival rate (\%) } \\
\cline { 5 - 8 } & & & Mean & SE & $1 \mathrm{yr}$ & $3 \mathrm{yr}$ & $5 \mathrm{yr}$ \\
\hline$\leq 224$ & 440 & 34 & 123.9 & 1.3 & 99 & 95 & 92 \\
225 to 253 & 16 & 2 & 70.5 & 3.3 & 100 & 94 & 87 \\
$\geq 254$ & 28 & 10 & 54.7 & 5.0 & 89 & 64 & 64 \\
\hline
\end{tabular}

Table 7. Multivariate Cox regression model for predictor of breast cancer.

\begin{tabular}{|c|c|c|c|c|c|}
\hline \multirow{2}{*}{ Variables } & \multirow{2}{*}{$\beta$} & \multirow{2}{*}{ Hazard ratio } & \multicolumn{2}{|c|}{$95 \%$ CI of HR } & \multirow{2}{*}{$\mathrm{P}$ value } \\
\hline & & & Lower & Upper & \\
\hline Age & 0.045 & 1.046 & 1.019 & 1.075 & $<0.001^{*}$ \\
\hline \multicolumn{6}{|l|}{ Stage } \\
\hline I (ref.) & & 1 & & & \\
\hline II & 1.137 & 3.118 & 1.029 & 9.443 & $0.044^{*}$ \\
\hline III & 1.793 & 6.006 & 1.915 & 18.832 & $0.002^{*}$ \\
\hline IV & 3.096 & 22.107 & 6.897 & 70.864 & $0.001^{*}$ \\
\hline \multicolumn{6}{|l|}{$\mathrm{P} / \mathrm{L}$ ratio } \\
\hline$\leq 224$ (ref.) & & 1 & & & \\
\hline 225 to 253 & 0.784 & 2.19 & 0.516 & 9.303 & 0.288 \\
\hline$\geq 254$ & 1.222 & 3.394 & 1.585 & 7.269 & $0.002^{*}$ \\
\hline \multicolumn{6}{|l|}{ OP } \\
\hline BCS (ref.) & & 1 & & & \\
\hline MRM & 0.524 & 1.689 & 0.501 & 5.686 & 0.398 \\
\hline
\end{tabular}

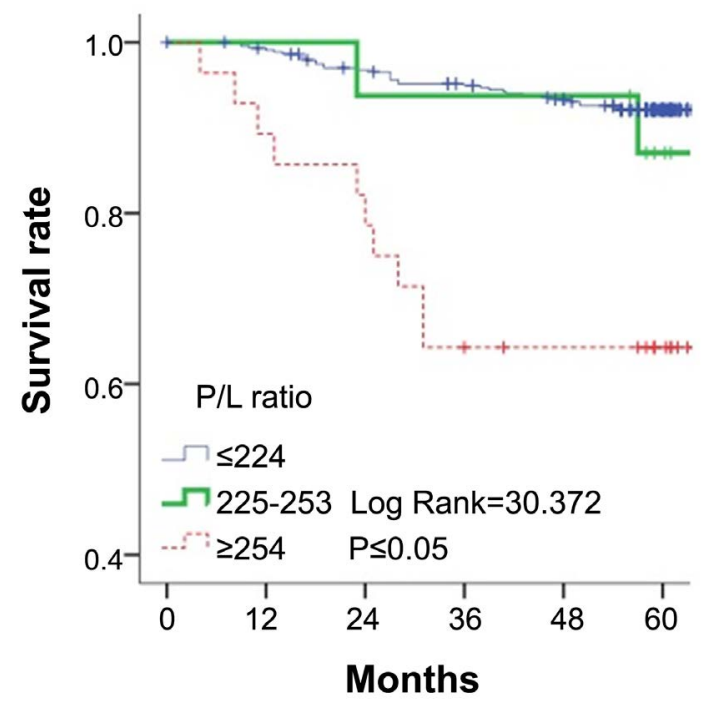

Figure 3. Analysis of five-year survival rate of Kaplan-Meier method in breast cancer patients divided into three groups according $\mathrm{P} / \mathrm{L}$ ratio $(\mathrm{P} \leq 0.05)$ with Log-rant test. 


\section{Discussion}

The relationship between the inflammatory cells and cancer has been demonstrated by accumulating studies [5] [20]. The pretreatment counts of peripheral inflammatory cells, including neutrophil, lymphocyte and platelet, have demonstrated the strong link between the inflammatory system and prognosis in cancer patients [21]. In particular, NLR and PLR have recently been reported to be significant prognostic factors even in other types of solid cancer [11] [12] [13] [14] [15].

In the neoplastic process, these inflammatory cells are powerful tumor promoters, tumor growth, facilitating genomic instability and promoting angiogenesis. The inflammatory cells will produce chemokines and cytokines that influence the whole tumor bio-enviroment, regulating the growth, migration and differentiation of all cell types in the tumor micro-environment [5] [7] [22] [23]. In addition, these inflammatory cells will release growth factors, promoting angiogenesis and lymphangiogenesis, remodelling the extra-cellular metaprotease to facilitate invasion, and disseminating cells via lymphatics or capillaries, and evading host defense mechanisms in breast cancer. Actually, in a fully developed malignancy, there are excess inflammatory cells in the tumor microenvironment and harbor altered risk for developing cancer or an indicators of prognosis [5] [24] [25]. In our series, the presences of positive breast cancer cells in the lympho-vessel, or lymph-node had a result of poor prognosis.

The role of neutrophils in cancer is multifactorial and reflect a state of host inflammation and they can participate in different stages of the oncogenic process including tumor initiation, growth, proliferation or metastasis [24] [26] [27]. In patients with solid cancers, neutrophils expand both in the tumor microenvironment and systemically, and are generally associated with poor prognosis due to neutrophils as key regulators of cross-talk with host cells and disseminating cancer cells [28]. Lymphocytes are a non-specific commonly used as a marker of host immunity [29] [30]. In recent years, many evidences have demonstrated that the lymphocyte count is an independent prognostic marker in various cancers, such as liver, colorectal, lung cancers in addition to breast cancer [30] [31] [32] [33] [34]. Besides, lymphocyte count and neutrophil-lymphocyte cell ratio were also evaluated with overall survival in advanced cancer patients [19] [29]. Taken together, these results suggested that a low level of lymphocytes may reflect a poor health status and poor prognosis in cancer patients. In our study, lymphocyte less than $16.6 \%$, the $1-y r, 3-y r$, and 5 -yr survival rate was poor than that of higher percentage of lymphocyte.

NLR is calculated from routine labs for patients and readily available allows it to be conveniently monitored. These clinical findings make NLR a biomarker easy to evaluate, and have potential for the identification of early responders and prognostic relevance associated with clinical outcome [35]. We should note that impact the worse outcome is the presence of inflammation and the neutrophils is an indirect risk and can vary among cancer cell types. However, the normal 
NLR values in an adult, non-geriatric, population in good health are between 0.78 and 3.53 [36]. The cutoff level of NLR ranged from 1.93 to 4.8 , which effected tendency on the prognosis of breast cancer patients, was reported from the literatures [21] [37] [38] [39]. In our series, the 5-year survival was $84 \%$ if NLR $\geq 2.58$ and had a same trends of higher NLR having a poor prognosis like other literatures [12] [13]. In a report regarding role of NLR in overall survival, there was no significant difference between patients with high and low NLR with 5-year overall survival of $90.8 \%$ and $91.7 \%(p=0.707)$. But in triple-negative breast cancer, patients with high NLR was associated with worse 5-year disease free survival rate compared with patients with low NLR $(63.4 \%$ vs $84.9 \%, \mathrm{p}=$ 0.040) [37]. On the contrary, patients with low NLR had a poorer 3-year disease free survival than patients with high NLR $(89.7 \%$ vs $94.0 \%, \mathrm{p}=0.047)$. Neither lymphocyte count nor NLR could predict overall survival independently. Particularly in HER-2-positive breast cancer patients who were treated with adjuvant Trastuzumab, a high lymphocyte count is significantly associated with a poor disease free survival [40].

Platelet granules contain abundance of cancer related factors including adhesion molecules, growth factors, and immunologic molecules [41]. Circulating cancer cells may encounter platelet-derived particles which may serve to activate the platelets and leads to metastasis [10] [42]. Therefore, platelets are well suited to serve as facilitated cancer progression and metastasis which will clearly affect the prognosis [42] [43] [44]. Elevated PLR was associated with reduced overall survival in patients with advanced cancer [17] [45] [46]. The cutoff level of PLR ranged from 104.4 to 250 which effected the prognosis of breast cancer patients, was reported from the literatures [13] [17] [46]. Our results had the same trend and mean survival was shorter if PLR elevated $\geq 254$ in our series. In another study suggested that breast cancer patients with low PLR $<150$, treated with neo-adjuvant chemotherapy achieve higher complete pathological response, independently of primary breast cancer molecular subtype [47]. Similarly, a PLR $\geq$ 250 was associated with worse overall survival rate $(\mathrm{p}<0.001)$ and only the PLR was more independently associated with worse outcomes in patients with breast cancer [17]. The combination of NLR and PLR may reflect patients' immunogenic phenotype. Low levels of both NLR and PLR may thus indicate a status of immune system activation that may predict pathological complete response in breast cancer patients treated with neoadjuvant chemotherapy [13]. Taken together, both increased neutrophil and platelet, and decreased lymphocyte that will drive the elevation either NLR or PLR, and will be a predictor for the poor prognosis of breast cancer patients by the routine clinical tests.

In a special subtype of triple negative breast cancer (TNBC) is a more aggressive subtype of breast cancer and this subtype has the poorest prognosis, compared to other subtypes of breast cancer. TNBC is found to have a higher NLR or PLR with a shorter survival rate and an increased tumor recurrence [48] [49]. Among 57 patients of TNBC patients findings suggest that NLR $\geq 2.5$ and PLR $\geq$ 200 are predictive of benefit from platinum-containing chemotherapy [50]. 
There were 72 patient of TNBC and NLR was $\geq 2.58$ in 21 (29.2\%) and PLR $\geq$ 254 in 4 (5.6\%) with poor survival rate in our series. There was still some limitations existed including the applying treatment methods in our patients who follow the treatment guideline under hospital cancer registry center. Therefore, there is still much work to be done before they might be used as validated prognostic markers to reach the clinical setting.

\section{Conclusion}

The peripheral inflammatory cell counts are players in cancer growth and have a potential role as predictors of survival curves of breast cancer after surgery. Neutrophil, lymphocyte, platelet counts, NLR or PLR are easily to take in our clinical practice and highly associated with an adverse survival rate in our patients. Therefore, we have to pay attention to the trends of peripheral inflammatory cell count and ratio in our practice in order to get a better survival rate by using the treatment modalities where possible.

\section{Contribution of Authors}

Study design: C.-G. Ker,

Data collection and registration: Chin-Yi Chao, Chia-Ling Lu,

Data biostastic analysis: Yu-Fu Chen, Bo-Wei Wang,

Interpretation and Manuscript writing: C.-G. Ker, P.-F. Chen.

\section{Conflicts of Interest}

There are no any of conflicts of interest of all authors listed in this manuscript or institution or product that is mentioned in the manuscript.

\section{References}

[1] MOHW (2018) Cancer Prevention. https://health99hpagovtw/Box2/Cancer/newsaspx

[2] Tokuda, Y., Yanagawa, M., Minamitani, K., Naoi, Y., Noguchi, S. and Tomiyama, N. (2020) Radiogenomics of Magnetic Resonance Imaging and a New Multi-Gene Classifier for Predicting Recurrence Prognosis in Estrogen Receptor-Positive Breast Cancer: A Preliminary Study. Medicine, 99, e19664. https://doi.org/10.1097/MD.0000000000019664

[3] Ou, Q., Cheng, J., Zhang, L., Wang, H., Wang, W. and Ma, Y. (2017) The Prognostic Value of Pretreatment Neutrophil-to-Lymphocyte Ratio in Breast Cancer: Deleterious or Advantageous? Tumour Biology: The Journal of the International Society for Oncodevelopmental Biology and Medicine, 39, 1010428317706214. https://doi.org/10.1177/1010428317706214

[4] Proctor, M.J., McMillan, D.C., Morrison, D.S., Fletcher, C.D., Horgan, P.G. and Clarke, S.J. (2012) A Derived Neutrophil to Lymphocyte Ratio Predicts Survival in Patients with Cancer. British Journal of Cancer, 107, 695-699. https://doi.org/10.1038/bjc.2012.292

[5] Coussens, L.M. and Werb, Z. (2002) Inflammation and Cancer. Nature, 420, 860-867. https://doi.org/10.1038/nature01322 
[6] Mantovani, A., Savino, B., Locati, M., Zammataro, L., Allavena, P. and Bonecchi, R. (2010) The Chemokine System in Cancer Biology and Therapy. Cytokine \& Growth Factor Reviews, 21, 27-39. https://doi.org/10.1016/j.cytogfr.2009.11.007

[7] Rollins, B.J. (2006) Inflammatory Chemokines in Cancer Growth and Progression. European Journal of Cancer (Oxford, England: 1990), 42, 760-767. https://doi.org/10.1016/j.ejca.2006.01.002

[8] Ludlam, C.A. (1980) The Assessment of Platelet Function in Vivo by Measurement of Beta-Thromboglobulin, Platelet Factor 4 and Platelet Survival. Artery, 8, 470-474.

[9] Dubernard, V., Arbeille, B.B., Lemesle, M.B. and Legrand, C. (1997) Evidence for an Alpha-Granular Pool of the Cytoskeletal Protein Alpha-Actinin in Human Platelets That Redistributes with the Adhesive Glycoprotein Thrombospondin-1 during the Exocytotic Process. Arteriosclerosis, Thrombosis, and Vascular Biology, 17, 2293-2305. https://doi.org/10.1161/01.ATV.17.10.2293

[10] Green, D.L. and Karpatkin, S. (2009) Effect of Cancer on Platelets. Cancer Treatment and Research, 148, 17-30. https://doi.org/10.1007/978-0-387-79962-9 2

[11] Yang, H.J., Guo, Z., Yang, Y.T., Jiang, J.H., Qi, Y.P., Li, J.J., et al. (2016) Blood Neutrophil-Lymphocyte Ratio Predicts Survival after Hepatectomy for Hepatocellular Carcinoma: A Propensity Score-Based Analysis. World Journal of Gastroenterology, 22, 5088-5095. https://doi.org/10.3748/wjg.v22.i21.5088

[12] Rashtak, S., Ruan, X., Druliner, B.R., Liu, H., Therneau, T., Mouchli, M., et al. (2017) Peripheral Neutrophil to Lymphocyte Ratio Improves Prognostication in Colon Cancer. Clinical Colorectal Cancer, 16, 115-123e3. https://doi.org/10.1016/j.clcc.2017.01.008

[13] Graziano, V., Grassadonia, A., Iezzi, L., Vici, P., Pizzuti, L., Barba, M., et al. (2019) Combination of Peripheral Neutrophil-to-Lymphocyte Ratio and Platelet-to-Lymphocyte Ratio Is Predictive of Pathological Complete Response after Neoadjuvant Chemotherapy in Breast Cancer Patients. Breast (Edinburgh, Scotland), 44, 33-38. https://doi.org/10.1016/j.breast.2018.12.014

[14] Deng, M., Ma, X., Liang, X., Zhu, C. and Wang, M. (2017) Are Pretreatment Neutrophil-Lymphocyte Ratio and Platelet-Lymphocyte Ratio Useful in Predicting the Outcomes of Patients with Small-Cell Lung Cancer? Oncotarget, 8, 37200-37207. https://doi.org/10.18632/oncotarget.16553

[15] Tas, M., Yavuz, A., Ak, M. and Ozcelik, B. (2019) Neutrophil-to-Lymphocyte Ratio and Platelet-to-Lymphocyte Ratio in Discriminating Precancerous Pathologies from Cervical Cancer. Journal of Oncology, 2019, Article ID: 2476082. https://doi.org/10.1155/2019/2476082

[16] Proctor, M.J., Morrison, D.S., Talwar, D., Balmer, S.M., Fletcher, C.D., O'Reilly, D.S., et al. (2011) A Comparison of Inflammation-Based Prognostic Scores in Patients with Cancer. A Glasgow Inflammation Outcome Study. European Journal of Cancer (Oxford, England: 1990), 47, 2633-2641. https://doi.org/10.1016/j.ejca.2011.03.028

[17] Ramos-Esquivel, A., Rodriguez-Porras, L. and Porras, J. (2017) Neutrophil-Lymphocyte Ratio and Platelet-Lymphocyte Ratio as Prognostic Factors in Non-Metastatic Breast Cancer Patients from a Hispanic Population. Breast Disease, 37, 1-6. https://doi.org/10.3233/BD-160251

[18] Fujii, T., Yanai, K., Tokuda, S., Nakazawa, Y., Kurozumi, S., Obayashi, S., et al. (2018) Relationship between FDG Uptake and Neutrophil/Lymphocyte Ratio in Patients with Invasive Ductal Breast Cancer. Anticancer Research, 38, 4927-4931. https://doi.org/10.21873/anticanres.12809

[19] Fujimoto, Y., Ozawa, H., Higuchi, T., Miyagawa, Y., Bun, A., Imamura, M., et al. 
(2019) Improved Prognosis of Low Baseline Neutrophil-to-Lymphocyte Ratio Is Significantly Exclusive in Breast Cancer Patients with High Absolute Counts of Lymphocytes. Molecular and Clinical Oncology, 10, 275-284. https://doi.org/10.3892/mco.2018.1783

[20] Dolan, R., Laird, B., Horgan, P. and McMillan, D. (2018) The Prognostic Value of the Systemic Inflammatory Response in Randomised Clinical Trials in Cancer: A Systematic Review. Critical Reviews in Oncology/ Hematology, 132, 130-137. https://doi.org/10.1016/j.critrevonc.2018.09.016

[21] Jia, W., Wu, J., Jia, H., Yang, Y., Zhang, X., Chen, K., et al. (2015) The Peripheral Blood Neutrophil-to-Lymphocyte Ratio Is Superior to the Lymphocyte-to-Monocyte Ratio for Predicting the Long-Term Survival of Triple-Negative Breast Cancer Patients. PLoS ONE, 10, e0143061. https://doi.org/10.1371/journal.pone.0143061

[22] Cho, U., Park, H.S., Im, S.Y., Yoo, C.Y., Jung, J.H., Suh, Y.J., et al. (2018) Prognostic Value of Systemic Inflammatory Markers and Development of a Nomogram in Breast Cancer. PLoS ONE, 13, e0200936. https://doi.org/10.1371/journal.pone.0200936

[23] Nishijima, T.F., Deal, A.M., Lund, J.L., Nyrop, K.A., Muss, H.B. and Sanoff, H.K. (2019) Inflammatory Markers and Overall Survival in Older Adults with Cancer. Journal of Geriatric Oncology, 10, 279-284. https://doi.org/10.1016/j.jgo.2018.08.004

[24] Coffelt, S.B., Wellenstein, M.D. and de Visser, K.E. (2016) Neutrophils in Cancer: Neutral No More. Nature Reviews Cancer, 16, 431-446. https://doi.org/10.1038/nrc.2016.52

[25] Ocana, A., Nieto-Jiménez, C., Pandiella, A. and Templeton, A.J. (2017) Neutrophils in Cancer: Prognostic Role and Therapeutic Strategies. Molecular Cancer, 16, 137. https://doi.org/10.1186/s12943-017-0707-7

[26] Swierczak, A., Mouchemore, K.A., Hamilton, J.A. and Anderson, R.L. (2015) Neutrophils: Important Contributors to Tumor Progression and Metastasis. Cancer and Metastasis Reviews, 34, 735-751. https://doi.org/10.1007/s10555-015-9594-9

[27] Dumitru, C.A., Lang, S. and Brandau, S. (2013) Modulation of Neutrophil Granulocytes in the Tumor Microenvironment: Mechanisms and Consequences for $\mathrm{Tu}$ mor Progression. Seminars in Cancer Biology, 23, 141-148. https://doi.org/10.1016/j.semcancer.2013.02.005

[28] Spiegel, A., Brooks, M.W., Houshyar, S., Reinhardt, F., Ardolino, M., Fessler, E., et al. (2016) Neutrophils Suppress Intraluminal NK Cell-Mediated Tumor Cell Clearance and Enhance Extravasation of Disseminated Carcinoma Cells. Cancer Discovery, 6, 630-649. https://doi.org/10.1158/2159-8290.CD-15-1157

[29] Zhao, W., Wang, P., Jia, H., Chen, M., Gu, X., Liu, M., et al. (2017) Lymphocyte Count or Percentage: Which Can Better Predict the Prognosis of Advanced Cancer Patients Following Palliative Care? BMC Cancer, 17, 514.

https://doi.org/10.1186/s12885-017-3498-8

[30] Liang, L., Zhu, J., Jia, H., Huang, L., Li, D., Li, Q., et al. (2016) Predictive Value of Pretreatment Lymphocyte Count in Stage II Colorectal Cancer and in High-Risk Patients Treated with Adjuvant Chemotherapy. Oncotarget, 7, 1014-1028. https://doi.org/10.18632/oncotarget.5835

[31] Cho, O., Oh, Y.T., Chun, M., Noh, O.K. and Lee, H.W. (2016) Radiation-Related Lymphopenia as a New Prognostic Factor in Limited-Stage Small Cell Lung Cancer. Tumour Biology: The Journal of the International Society for Oncodevelopmental Biology and Medicine, 37, 971-978. https://doi.org/10.1007/s13277-015-3888-y 
[32] Tredan, O., Manuel, M., Clapisson, G., Bachelot, T., Chabaud, S., Bardin-dit- Courageot, C., et al. (2013) Patients with Metastatic Breast Cancer Leading to CD4+ T Cell Lymphopaenia Have Poor Outcome. European Journal of Cancer (Oxford, England: 1990), 49, 1673-1682. https://doi.org/10.1016/j.ejca.2012.11.028

[33] Wild, A.T., Ye, X., Ellsworth, S.G., Smith, J.A., Narang, A.K., Garg, T., et al. (2015) The Association between Chemoradiation-Related Lymphopenia and Clinical Outcomes in Patients with Locally Advanced Pancreatic Adenocarcinoma. American Journal of Clinical Oncology, 38, 259-265.

https://doi.org/10.1097/COC.0b013e3182940ff9

[34] Li, C., Wen, T.-F., Yan, L.-N., Li, B., Yang, J.-Y., Xu, M.-Q., et al. (2013) Scoring Selection Criteria Including Total Tumour Volume and Pretransplant Percentage of Lymphocytes to Predict Recurrence of Hepatocellular Carcinoma after Liver Transplantation. PLOS ONE, 8, e72235. https://doi.org/10.1371/journal.pone.0072235

[35] Asano, Y., Kashiwagi, S., Onoda, N., Noda, S., Kawajiri, H., Takashima, T., et al. (2016) Predictive Value of Neutrophil/Lymphocyte Ratio for Efficacy of Preoperative Chemotherapy in Triple-Negative Breast Cancer. Annals of Surgical Oncology, 23, 1104-1110. https://doi.org/10.1245/s10434-015-4934-0

[36] Forget, P., Khalifa, C., Defour, J.-P., Latinne, D., Van Pel, M.-C. and De Kock, M. (2017) What Is the Normal Value of the Neutrophil-to-Lymphocyte Ratio? BMC Research Notes, 10, 12. https://doi.org/10.1186/s13104-016-2335-5

[37] Hong, J., Mao, Y., Chen, X., Zhu, L., He, J., Chen, W., et al. (2016) Elevated Preoperative Neutrophil-to-Lymphocyte Ratio Predicts Poor Disease-Free Survival in Chinese Women with Breast Cancer. Tumour Biology. The Journal of the International Society for Oncodevelopmental Biology and Medicine, 37, 4135-4142. https://doi.org/10.1007/s13277-015-4233-1

[38] Kim, H.Y., Kim, T.H., Yoon, H.K. and Lee, A. (2019) The Role of Neutrophil-Lymphocyte Ratio and Platelet-Lymphocyte Ratio in Predicting Neoadjuvant Chemotherapy Response in Breast Cancer. Journal of Breast Cancer, 22, 425-438. https://doi.org/10.4048/jbc.2019.22.e41

[39] Xuan, Q., Yang, Y., Ji, H., Tang, S., Zhao, J., Shao, J., et al. (2019) Combination of the Preoperative Albumin to Globulin Ratio and Neutrophil to Lymphocyte Ratio as a Novel Prognostic Factor in Patients with Triple Negative Breast Cancer. Cancer Management and Research, 11, 5125-5131. https://doi.org/10.2147/CMAR.S195324

[40] Hong, J., Chen, X., Gao, W., Zhu, S., Wu, J., Huang, O., et al. (2019) A High Absolute Lymphocyte Count Predicts a Poor Prognosis in HER-2-Positive Breast Cancer Patients Treated with Trastuzumab. Cancer Management and Research, 11, 3371-3379. https://doi.org/10.2147/CMAR.S187233

[41] Menter, D.G., Tucker, S.C., Kopetz, S., Sood, A.K., Crissman, J.D. and Honn, K.V. (2014) Platelets and Cancer: A Casual or Causal Relationship: Revisited. Cancer and Metastasis Reviews, 33, 231-269. https://doi.org/10.1007/s10555-014-9498-0

[42] Menter, D.G., Kopetz, S., Hawk, E., Sood, A.K., Loree, J.M., Gresele, P., et al. (2017) Platelet "First Responders" in Wound Response, Cancer, and Metastasis. Cancer and Metastasis Reviews, 36, 199-213. https://doi.org/10.1007/s10555-017-9682-0

[43] Wojtukiewicz, M.Z., Sierko, E., Hempel, D., Tucker, S.C. and Honn, K.V. (2017) Platelets and Cancer Angiogenesis Nexus. Cancer and Metastasis Reviews, 36, 249-262. https://doi.org/10.1007/s10555-017-9673-1

[44] Xu, X.R., Zhang, D., Oswald, B.E., Carrim, N., Wang, X., Hou, Y., et al. (2016) Platelets Are Versatile Cells: New Discoveries in Hemostasis, Thrombosis, Immune Responses, Tumor Metastasis and Beyond. Critical Reviews in Clinical Laboratory 
Sciences, 53, 409-430. https://doi.org/10.1080/10408363.2016.1200008

[45] Li, B., Zhou, P., Liu, Y., Wei, H., Yang, X., Chen, T., et al. (2018) Platelet-to-Lymphocyte Ratio in Advanced Cancer: Review and Meta-Analysis. Clinica Chimica Acta; International Journal of Clinical Chemistry, 483, 48-56. https://doi.org/10.1016/j.cca.2018.04.023

[46] De Giorgi, U., Mego, M., Scarpi, E., Giordano, A., Giuliano, M., Valero, V., et al. (2019) Association between Circulating Tumor Cells and Peripheral Blood Monocytes in Metastatic Breast Cancer. Therapeutic Advances in Medical Oncology, 11, 1758835919866065. https://doi.org/10.1177/1758835919866065

[47] Cuello-Lopez, J., Fidalgo-Zapata, A., Lopez-Agudelo, L. and Vasquez-Trespalacios, E. (2018) Platelet-to-Lymphocyte Ratio as a Predictive Factor of Complete Pathologic Response to Neoadjuvant Chemotherapy in Breast Cancer. PLoS ONE, 13, e0207224. https://doi.org/10.1371/journal.pone.0207224

[48] Bao, B. and Prasad, A.S. (2019) Targeting CSC in a Most Aggressive Subtype of Breast Cancer TNBC. Advances in Experimental Medicine and Biology, 1152, 311. https://doi.org/10.1007/978-3-030-20301-6 17

[49] Ren, K., Yin, Y., He, F., Shao, Y. and Wang, S. (2018) Prognostic Role of Derived Neutrophil-to-Lymphocyte Ratio in Surgical Triple-Negative Breast Cancer. Cancer Management and Research, 10, 4891-4898. https://doi.org/10.2147/CMAR.S180695

[50] Vernieri, C., Mennitto, A., Prisciandaro, M., Huber, V., Milano, M., Rinaldi, L., et al. (2018) The Neutrophil-to-Lymphocyte and Platelet-to-Lymphocyte Ratios Predict Efficacy of Platinum-Based Chemotherapy in Patients with Metastatic Triple Negative Breast Cancer. Scientific Reports, 8, Article No. 8703.

https://doi.org/10.1038/s41598-018-27075-Z 